\title{
Business Faculty in Canadian Universities: Importance and Satisfaction Related to Job Characteristics*
}

\author{
SLAVEK J. HURKA**
}

\begin{abstract}
This paper examines the relationship between the importance and satisfaction of various job characteristics as perceived by 322 business faculty members teaching in 15 Canadian universities. The findings suggest that those aspects which the respondents felt to be most important were also those with which they were the least satisfied.
\end{abstract}

\section{RESUME}

Cette étude fail l'analyse des rapports entre l'importance et la satisfaction de diverses caractéristiques de l'emploi telles que perçues par 322 membres du corps enseignant de la Faculté des affaires commerciales à 15 universités canadiennes. Les résultats de l'enquête suggèrent que les aspects estimés les plus importants par les répondants étaient en même temps ceux avec lesquels ils exprimaient le moins de satisfaction.

A number of studies have investigated and analyzed the relationship between employees and the organization with which they are associated. The research in this field dealing with professional employees has focused on strains between professional values and the demands guiding the behavior of employing organizations.

Kornhauser's (1962) study of engineers and scientists is a study of strains and accommodations between professions and organizations. In his investigation dealing with the effects of employment of scientists by industry, Marcson (1960) found that the demands

*The author wishes to thank Michael Hurka for his assistance in collection and analysis of data.

**Slavek J. Hurka, Associate Professor of Organizational Behavior, College of Commerce,

University of Saskatchewan. 
of professionals for "self-rule" is very much in evidence when he stated that "the professional tends to resent authority which originates outside the professional unit" (1960, p. 124). He differentiated between two types of authority, the "executive" and the "colleague" authority; the first rests with the organization, the latter with the professional group. Perhaps the best known study of the conflict between professional and organizational commitment is that of Gouldner (1958), which was carried out in a private liberalarts college. The aim of his research was to measure loyalty to the organization, commitment to specialized professional skills, and reference group orientation. His findings have shown that high commitment to professional skills and the orientation to outside reference groups were associated with low loyalty to the organization. Similar observations were made by Hurka (1972) in his study of nurses working in hospitals. The nurses considered their freedom to make major nursing decisions to be most important and, like other professionals, they tended to be critical of the administration and indicated a low loyalty to the employing organization. In a study investigating the legal profession, Smigel (1964) concludes that while the lawyer is required to conform to the demands of the organization, intellectually he remains a "free" man. However, he is concerned with the future of the legal profession and fears that as the number and size of large firms increase, the traditional independence of the lawyers may be adversely affected. He predicts that conflict between the increased bureaucratic system and the lawyer will grow (1964, p. 351). Finally, a more recent study of certified public accountants in large public accounting firms showed that when professionals work in a professional-bureaucratic organization, conflict inevitably results in job dissatisfaction and job migration (Sorensen and Sorensen, 1974). In short, a great many studies indicate that professionals are uncomfortable with bureaucratic authority, at least to the extent of expressing dissatisfaction with supervisory arrangements.

\section{Purpose}

This study focused on another group of professional workers: the business school faculty in Canadian universities. It had two major objectives. First, it attempted to identify characteristics which the faculty considered to be important in performing the job. The second purpose was to determine the degree of satisfaction, as perceived by the respondents, using their current position as a frame of reference. Specifically, answers to the following questions were sought:

- What job characteristics are considered to be important by the faculty teaching business (commerce) subjects in selected institutions of higher education in Canada?

- How satisfied or dissatisfied are the faculty members with the identified characteristics (deemed to be important) when relating them to their current position?

- What degree of professional autonomy (or administrative control) do faculty members experience compared to the identified characteristics?

\section{Method}

The data for this study were gathered during the summer of 1977 from faculty members in fifteen Canadian schools of business which offer a graduate program in business administration. The population selected for this study consisted of full-time faculty with a rank of 
instructor or higher. The questionnaire was mailed, along with a self-addressed, stamped return envelope to 623 faculty members in selected schools. At the end of data collection, 332 questionnaires had been returned, representing a response of 52 percent. Of this total, ten questionnaires were incomplete and, therefore, not included in the study. Consequently, 332 questionnaires, comprising a 50 percent of the total population, were used for analysis. The response from individual schools ranged from 45 to 77 percent.

A two part instrument was used to gather the data. The "Job Characteristics" instrument used in the study represents a modification of a scale developed and validated by Bonjean and Vance $(1968,1976)$. The respondents were asked to indicate how important they would consider each characteristic if they were "looking for a position within the field for which they are qualified". A four-point scale was utilized to measure the responses in the following manner: 4 - "most important"; 3 - "next in importance"; 1 - "some importance" and 0 - "no importance". Having developed his own list of ideal job characteristics, the faculty member was asked to consider the characteristics in the context of his present position. For each item marked as having at least some importance, the respondent was asked to indicate if he would rate his own situation as "completely satisfactory", "satisfactory but should be better", "barely satisfactory", or "completely unsatisfactory". Satisfaction responses were scored 3,2, 1, 0, respectively. "Background Information" constituted the second part of the questionnaire and was designed to obtain such data as rank, department, number of years teaching and similar information.

Data from the completed questionnaires were scored, coded, and key-punched onto data-processing cards. Analytic procedures in the Statistical Package for Social Sciences (Nie, et al.1970) and facilities of the University of Saskatchewan Computer Centre were used.

\section{Importance of Job Characteristics}

The means and ranks which the faculty members associated with each job characteristic are presented in Table 1. The first two columns in the Table indicate the importance scores followed by satisfaction scores in the next two columns.

The most important aspect of work perceived by the respondents was to have time and facilities to do quality research. The opportunity to work with supportive colleagues ranked second in importance. These two items were followed by "having bright and stimulating students" in the class. Salary ranked fourth, and the opportunity to be a good teacher was the fifth most important aspect of an ideal teaching position. The desire for autonomy was reflected in ranking non-directive dean - a dean who "lets me define my own responsibilities and permits me to fulfill them in my own way" - as the next most important item. Two other questions dealt with autonomy at work: "being left alone" (item 5), and "available dean" (item 10). The desire for freedom of work was underscored by the faculty responding to the questionnaire in ranking "availability of dean" second last with a mean importance score of .84 , while "being left alone" was ranked in 12 th with a mean importance score of 1.80 .

The literature dealing with professionals working in organizations suggests that participation in decision making is an important attribute to most professionals. Two items in the questionnaire were designed to get a response related to participation: "having a voice in determining the policy of the school" (item 9), and "having responsi- 
Importance and Satisfaction Scores for 21 Job Characteristics of a Business Faculty Position

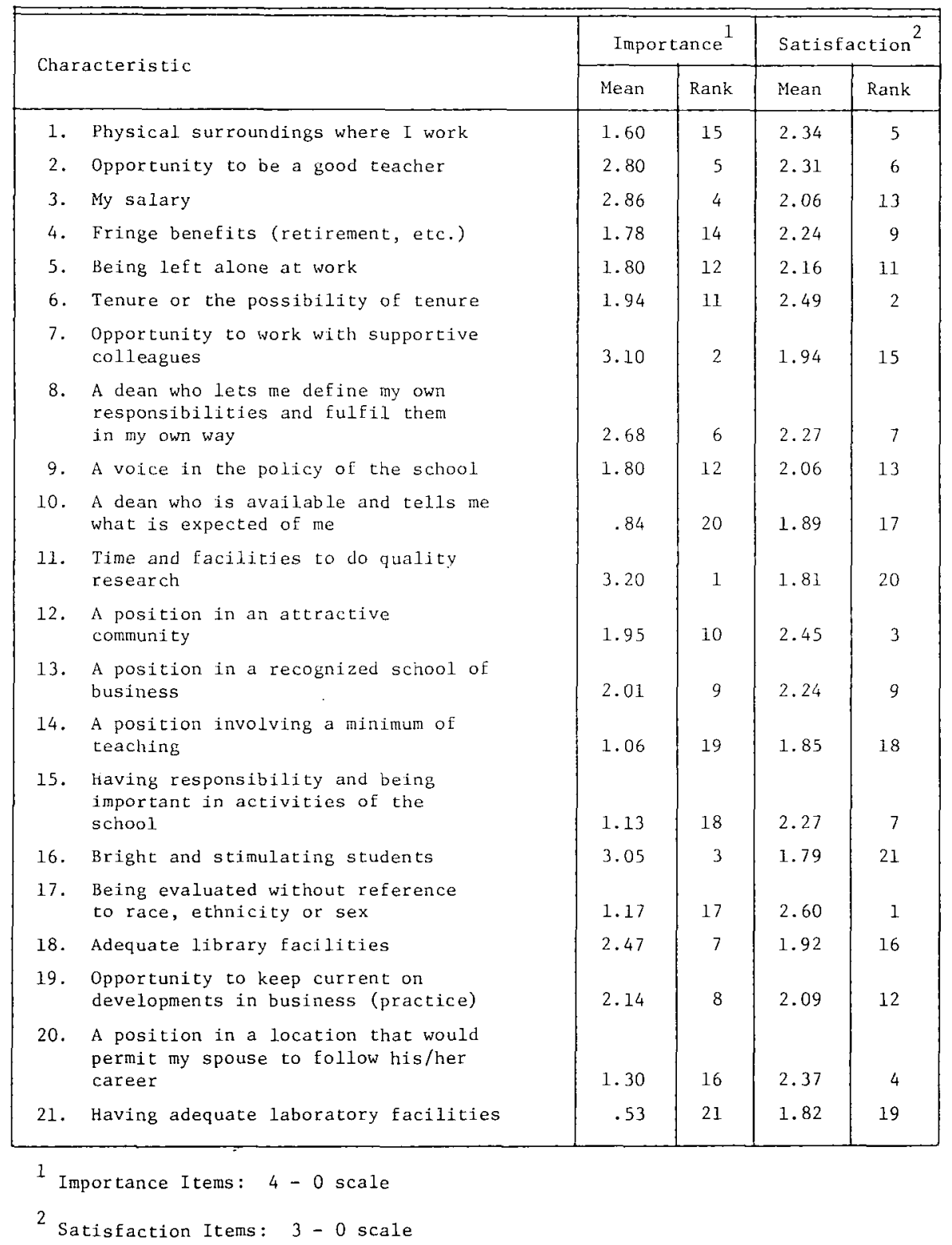

bility and being important in activities of the school" (item 15). These two items ranked 12 th and 18 th in importance, respectively. The results seem to suggest that, unlike other professionals, participation in decision making is not a great concern to business faculty. At least two explanations can be offered for the relatively low ranking of these two items. One would be to speculate that most Canadian schools of business and their administrators 
practice participatory management in administering their activities, and, therefore, these two aspects of work are not important to faculty members. Evidence in support of this explanation is contained in satisfaction scores, especially with respect to "responsibility in school activities" (item 15). Although considered as a relatively unimportant aspect of their work, the mean score indicates relatively high satisfaction, ranking "responsibility" in seventh place. The second explanation may have to do with the environment and pressures facing the institutions of higher learning at present.

Current forecasts indicate a levelling-off in enrolment at Canadian universities before the end of the decade. This has not occurred thus far. During the five years between 1971/72 and 1975/76 the enrolment of full-time undergraduate students in Canada showed an 18.6 percent increase and a staggering increase of 66.7 percent in business student population. (Statistics Canada, Annual a). Increased teaching load, larger classes, and a shortage of instructors experienced by most business schools in recent year may, in part, explain the relatively low concern of the faculty in participating in the decision making process. Indeed, having ranked "quality research" and "teaching" - job charaacteristics which tend to gain respect and reward (Luthans, 1967) - among the most important aspects of their work may suggest that professional orientation is far more important to the members of the faculty than the administrative aspect of their work.

\section{Satisfaction with Job Characteristics}

The data in Table 2 were rearranged to show the most important job characteristics with a mean importance score of 2.00 or higher. The items are shown in order of importance and compared with ranks obtained from satisfaction scores.

TABLE 2

Most Important Job Characteristics

Compared with Satisfaction Scores

\begin{tabular}{|c|c|c|c|c|}
\hline \multicolumn{2}{|c|}{ Importance } & \multirow[b]{2}{*}{ Characteristic } & \multicolumn{2}{|c|}{ Satisfaction } \\
\hline Rank & íean ${ }^{1}$ & & Rank & $\operatorname{Mean}^{2}$ \\
\hline 1 & 3.20 & Quality Research $(11)^{3}$ & 20 & 1.81 \\
\hline 2 & 3.10 & Supportive Colleagues (7) & 15 & 1.94 \\
\hline 3 & 3.05 & Bright Students (16) & 21 & 1.82 \\
\hline 4 & 2.86 & Salary (3) & 13 & 2.06 \\
\hline 5 & 2.80 & Teaching (2) & 6 & 2.31 \\
\hline 6 & 2.68 & Non-directive dean $(8)$ & 7 & 2.27 \\
\hline 7 & 2.47 & Library (18) & 16 & 1.92 \\
\hline 8 & 2.14 & Keeping up to date on knowledge (19) & 12 & 2.09 \\
\hline 9 & 2.01 & iNational recognition (13) & 9 & 2.24 \\
\hline
\end{tabular}

1 Importance Items: 4-0 scale

2 Satisfaction Items: 3-0 scale

3 Indicates the order of job characteristic 
Table 2 reveals a generally low level of satisfaction for most of the more important items. The most important characteristic of an ideal position, quality research, ranked 20 th in satisfaction. More than a third of the respondents found their present situation less than "barely satisfactory" in this regard. On the other hand, the characteristic with which the respondents expressed most satisfaction - to be evaluated without reference to race, ethnicity or sex - was considered relatively unimportant in 17 th rank. Working with supportive colleagues ranked second in importance but the mean satisfaction score indicated a low 15 th rank. The results indicate that business faculty is least satisfied with the third most important aspect of their work: having bright and stimulating students. The finding here is especially noteworthy because the dissatisfaction with this aspect of faculty work was evident in most of the schools. Respondents from eleven of the fifteen schools surveyed ranked this item among the five lowest on the satisfaction scale, and only two schools appeared to be satisfied with their students, ranking them 6 th and 9 th respectively. Of the nine more important job characteristics only three - teaching, nondirective dean, and national recognition - were accorded a relatively high satisfaction.

\section{Analysis of Results by Region}

The scores for importance and satisfaction were computed for each job characteristic for the fifteen schools of business and were grouped into four regions in Table 3. (Ec. Council

TABLE 3

Importance of Job Characteristics (By Region)

\begin{tabular}{|c|c|c|c|c|c|c|c|c|}
\hline & \multicolumn{8}{|c|}{ REGION } \\
\hline & \multicolumn{2}{|c|}{$\bar{A}$} & \multicolumn{2}{|c|}{ B } & \multicolumn{2}{|c|}{$\bar{C}$} & \multicolumn{2}{|r|}{$\mathrm{D}$} \\
\hline & Mean & Rank & Mean & Rank & Mean & Rank & Mean & Rank \\
\hline 1. Surroundings & 1.45 & 17 & 1.73 & 16 & 1.76 & 14 & 1.48 & 15 \\
\hline 2. Teaching & 2.15 & 8 & 3.67 & 1 & 2.86 & 5 & 2.80 & 5 \\
\hline 3. Salary & 3.08 & 2 & 2.80 & 6 & 2.94 & 4 & 2.70 & 6 \\
\hline 4. Fringe Benefits & 1.83 & 12 & 2.33 & 12 & 1.80 & 11 & 1.63 & 14 \\
\hline 5. Being left alone & 2.08 & 9 & 1.87 & 14 & 1.69 & 15 & 1.75 & 11. \\
\hline 6. Tenure & 1.70 & 14 & 2.47 & 9 & 2.16 & 8 & 1.68 & 12 \\
\hline 7. Supportive colleagues & 3.00 & 4 & 3.20 & 2 & 3.16 & 2 & 3.03 & 3 \\
\hline 8. Non-directive dean & 3.00 & 4 & 2.47 & 9 & 2.42 & 7 & 2.89 & 4 \\
\hline 9. Policy voice & 1.96 & 10 & 2.27 & 13 & 1.80 & 11 & 1.66 & 13 \\
\hline 10. Available Dean & 0.80 & 20 & 0.60 & 21 & 0.82 & 20 & 0.86 & 19 \\
\hline 11. Quality research & 3.33 & 1 & 2.87 & 4 & 3.26 & 1 & 3.08 & 2 \\
\hline 12. Attractive community & 1.88 & 11 & 2.60 & 7 & 1.95 & 10 & 1.89 & 10 \\
\hline 13. National recognition & 2.23 & 7 & 2.53 & 8 & 1.77 & 13 & 2.06 & 9 \\
\hline 14. Minimal teaching & 1.63 & 15 & 0.67 & 20 & 1.10 & 19 & 0.84 & 20 \\
\hline 15. Responsibility & 1.30 & 18 & 1.87 & 14 & 1.12 & 18 & 0.95 & 18 \\
\hline 16. Bright students & 3.08 & 2 & 2.87 & 4 & 2.99 & 3 & 3.11 & 1 \\
\hline 17. No discrimination & 1.25 & 19 & 1.33 & 18 & 1.17 & 16 & 1.04 & 17 \\
\hline 18. Library & 2.38 & 6 & 3.00 & 3 & 2.68 & 6 & 2.14 & 7 \\
\hline 19. Current development knowledge & 1.75 & 13 & 2.40 & 11 & 2.15 & 9 & 2.14 & 7 \\
\hline 20. Spouse's career & 1.58 & 16 & 1.53 & 17 & 1.17 & 16 & 1.34 & 16 \\
\hline 21. Laboratory & 0.58 & 21 & 0.93 & 19 & 0.56 & 21 & 0.37 & 21 \\
\hline
\end{tabular}




\begin{tabular}{|c|c|c|c|c|c|c|c|c|}
\hline \multicolumn{9}{|c|}{$\begin{array}{r}\text { Satisfaction with Job Characteristics } \\
\text { (By Region) }\end{array}$} \\
\hline & \multicolumn{8}{|c|}{ REGION } \\
\hline & \multicolumn{2}{|c|}{$\mathrm{A}$} & \multicolumn{2}{|c|}{$B$} & \multicolumn{2}{|c|}{ C } & \multicolumn{2}{|c|}{$\bar{D}$} \\
\hline & Mean & Rank & Mean & Rank & Mean & Rank & Mean & Rank \\
\hline 1. Surroundings & 1.90 & 15 & 1.92 & 14 & 2.46 & 4 & 2.41 & 6 \\
\hline 2. Teaching & 2.10 & 13 & 2.43 & 3 & 2.23 & 6 & 2.42 & 5 \\
\hline 3. Salary & 2.38 & 4 & 1.36 & 21 & 2.07 & 11 & 2.03 & 17 \\
\hline 4. Fringe Benefits & 2.49 & 3 & 1.92 & 14 & 2.22 & 7 & 2.24 & 11 \\
\hline 5. Being left a lone & 2.31 & 6 & 2.40 & 4 & 2.03 & 12 & 2.22 & 12 \\
\hline 6. Tenure & 2.51 & 2 & 2.08 & 12 & 2.64 & 1 & 2.36 & 8 \\
\hline 7. Supportive colleagues & 1.61 & 18 & 2.21 & 7 & 1.91 & 14 & 2.08 & 16 \\
\hline 8. Non-directive dean & 2.22 & 10 & 2.46 & 1 & 2.18 & 9 & 2.36 & 8 \\
\hline 9. Policy voice & 2.14 & 11 & 2.25 & 6 & 1.98 & 13 & 2.09 & 15 \\
\hline 10. Available Dean & 2.29 & 7 & 2.14 & 11 & 1.69 & 19 & 1.87 & 21 \\
\hline 11. Quality research & 1.53 & 19 & 1.58 & 20 & 1.78 & 18 & 1.97 & 20 \\
\hline 12. Attractive community & 2.24 & 9 & 2.46 & 1 & 2.50 & 3 & 2.52 & 2 \\
\hline 13. National recognition & 2.12 & 12 & 2.17 & 9 & 2.12 & 10 & 2.43 & 4 \\
\hline 14. Minimal teaching & 1.46 & 20 & 1.88 & 17 & 1.85 & 16 & 2.02 & 18 \\
\hline 15. Responsibility & 2.29 & 7 & 2.15 & 10 & 2.22 & 7 & 2.37 & 7 \\
\hline 16. Bright students & 1.20 & 21 & 1.92 & 14 & 1.67 & 20 & 2.10 & 14 \\
\hline 17. No discrimination & 2.61 & 1 & 2.18 & 8 & 2.58 & 2 & 2.72 & 1 \\
\hline 18. Library & 1.82 & 16 & 1.64 & 1.9 & 1.80 & 17 & 2.13 & 13 \\
\hline 19. Current development knowledge & 2.10 & 13 & 1.86 & 18 & 1.88 & 15 & 2.35 & 10 \\
\hline 20. Spouse's career & 2.38 & 4 & 2.40 & 4 & 2.25 & 5 & 2.44 & 3 \\
\hline 21. Laboratory & 1.81 & 17 & 2.00 & 13 & 1.62 & $\cdot 21$ & 2.00 & 19 \\
\hline
\end{tabular}

of Canada, 1971, p. 188). Since anonymity was guaranteed to the respondents, they were identified as Region A, B, C, and D.

Spearman rank-order correlation coefficient was computed for each pair. The association between the importance rankings for each pair of regions is reported in Table 4.

The correlation between the mean importance-score rankings for the four regions have a mean value of +.91 which suggests a high degree of similarity among business faculty in ranking the importance of the 21 ideal job characteristics.

TABLE 4

Association between the Importance Ranking in Four Regions

\begin{tabular}{|c|c|c|c|c|}
\hline \multirow{2}{*}{ Region } & \multicolumn{4}{|c|}{ Region } \\
\cline { 2 - 5 } & A & B & C & D \\
\hline A & & $.84^{*}$ & $.90 *$ & $.92 *$ \\
B & & & $.92^{*}$ & $\begin{array}{l}.95 * \\
.95 *\end{array}$ \\
C & & & & \\
\hline
\end{tabular}

$* \mathrm{p}<.001$ 
The results for the association between the satisfaction ranking in the four regions are shown in Table 5 .

The correlation between the mean satisfaction-score rankings for the four regions had a mean value of +.54 . As was the case with the importance scores, the mean of the coefficients for satisfaction scores indicated also a high degree of similarity among the respondents in the four regions, although variations from region to region remained noticeable. Table 3 indicated there was a considerable satisfaction in every region with the location that would permit the spouse to follow his/her career (Item 20) and agreement that the time and facilities available for research were not well satisfied (Item 11). However, there were also variations in satisfaction among the faculty in various regions. For example, faculty in region A were considerably more satisfied with salary and fringe benefits at their universities than the faculties in the other three regions (Item 3 and 4), while satisfaction with non-directive dean in region A was considerably higher.

Coefficients in Table 6 indicate the correlations between importance and satisfaction scores within each region.

As indicated above, all the correlations were negative, adding support to earlier findings which indicated that business faculty in the four regions did not tend to be most highiy satisfied with the job characteristics they perceived as most important.

TABLE 5

Association between the Satisfaction Ranking in Four Regions

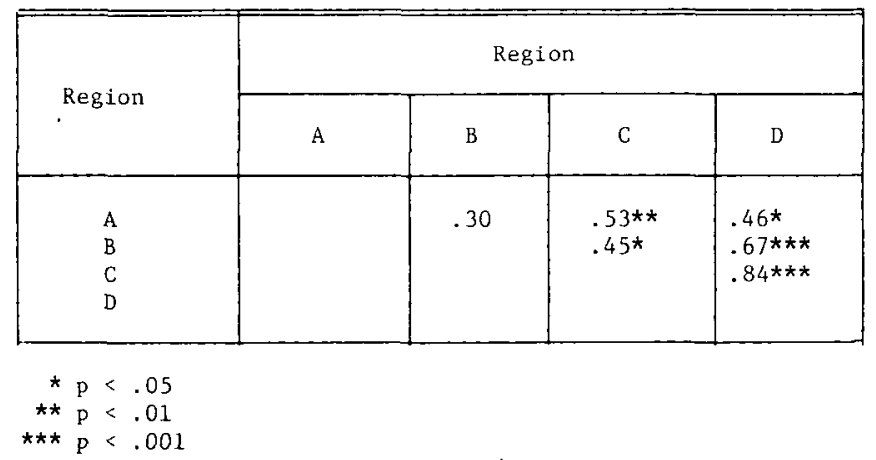

TABLE 6

Association between Importance and Satisfaction Within Region

\begin{tabular}{|c|c|}
\hline Region & $\begin{array}{c}\text { Spearman Rark } \\
\text { Correlation Coefficient }\end{array}$ \\
\hline A & -.04 \\
B & -.03 \\
C & -.06 \\
D & -.18 \\
\hline
\end{tabular}




\section{Summary and Conclusions}

Findings of this study suggested that the opportunity to use their skills, to associate with supportive colleagues, and to be challenged by stimulating students, are among the most important job characteristics to business faculty teaching at Canadian universities. Teaching, the other intrinsic aspect of the job, ranks fifth in importance. It is preceded by the concern for material rewards. The desire for autonomy at work is clearly evident from the results.

In spite of the similarity in scores reported earlier, the generalizations about relative satisfaction must be tentative because of the variation which exists in different schools and regions. Perhaps the most revealing information is that the job aspects with which the respondents are most satisfied are, on the whole, not the ones they are primarily concerned with. On the other hand, the more important items such as having time and facilities to conduct research and having bright students, rank among the least satisfying of all job characteristics. In addition, while the dissatisfaction with having time and facilities to engage in research is substantial and stable from region to region, the relatively high satisfaction with tenure policy is subject to considerable variation in different schools and regions.

The findings in this study should be of interest to faculty members and to administrators of business schools. In its present form, however, the results have a limited practical use since the data for individual schools are not reported. Unlike the deans and administrative staff in most non-professional colleges and schools, the business school administrators in Canada are still faced with the problems of increasing student enrolment. Coupled with the student expansion are at least two related problems of retention of good faculty and recruitment of new faculty. In the five year period ending in academic year 1975-76, the faculty in Canadian schools of business increased by 46 percent, compared to an increase of 14 percent for the entire faculty teaching in all Canadian universities (Statistics Canada, Annual b). It appears appropriate to suggest that a study which would assess the importance and satisfaction associated with different aspects of business school faculty positions could provide useful information to aid in more effective management of the schools.

\section{REFERENCES}

1. Bonjean, C.M. and G.G. Vance, "A Short-form Measure of Self-Actualization", Joumal of Applied Science, Vol. 4 (1968), 299-312.

2. Gouldner, A.W., "Cosmopolitans and Locals: Toward an Analysis of Latent Social Roles - I", Administrative Science Quarterly, Vol. 2 (1957), 281-306.

3. Grandjean, B.C., L.H. Aiken, and C.M. Bonjean, "Professional Autonomy and Work Satisfaction of Nursing Educators", Nursing Research, Vo. 25 (1976), 216-221.

4. Hurka, S.J., "Career Orientation of Registered Nurses Working in Hospitals", Hospital Administration, Vol. 17 (1972), 26-34.

5. Kornhauser, W., Scientists in Industry: Conflict and Accommodation, (Berkeley and Los Angeles: University of California, 1962).

6. Luthans, F., "Faculty Promotions: An Analysis of Central Administrative Control", Academy of Management Journal, Vol. 10 (1967), 385-394.

7. Marcson, S., The Scientist in American Industry, (Princeton, N.J.: Industrial Relations Section, Princeton University, 1960). 
8. Nie, N.H., et al, Statistical Package for the Social Sciences, Second Edition (New York: McGrawHill Book Co., 1975).

9. Smigel, E.O., The Wall Street Lawyer (Glencoe: Free Press, 1964).

10. Statistics Canada, Fall Enrollment in Universities, Catalogue No. 81-204 (Ottawa: Queen's Printer, Annual a).

11. Statistics Canada, Teachers in Universities, Part III, Qualifications and Age, Catalogue No. 81-243 (Ottawa: Queen's Printer, Annual b).

12. Von Zur-Muehlen, M., Business Education and Faculty at Canadian Universities (Ottawa: Information Canada, 1971). 